\title{
Report of the first clinical case of intestinal trichomoniasis caused by Tritrichomonas foetus in a cat with chronic diarrhoea in Brazil
}

\author{
Aline S. Hora ${ }^{1 *}$, Samantha I. Miyashiro², Fabiana C. Cassiano ${ }^{3}$, Paulo E. Brandão ${ }^{1}$, Archivaldo Reche-Junior ${ }^{2}$ \\ and Hilda F. J. Pena ${ }^{1}$
}

\begin{abstract}
Background: Tritrichomonas foetus is an emergent and important enteric pathogen of cats, which causes prolonged diarrhoea in cats.

Case presentation: This study describes a T. foetus infection in a seven-month-old, entire male domestic shorthair kitten with a six-month history of persistent large intestinal diarrhoea, faecal incontinence, prostration, apathy and weight loss. Parasites were microscopically observed and confirmed by PCR and DNA sequencing. Molecular analyses were carried out comparing the sequence obtained in this study with T. foetus and T. suis. Retrieved from GenBank. After treatment with ronidazole, the cat showed resolution of clinical signs.

Conclusions: This is the first clinical case of T. foetus infection in a chronic diarrheic cat in Brazil and South America, confirming the presence of this pathogen in this part of the world and highlighting the importance of this protozoa being considered in the differential diagnosis of cats presenting diarrhoea of the large intestine. Our case report enriches our knowledge on the geographical distribution of T. foetus in cats in Brazil and provides further understanding of the clinical significance of feline intestinal trichomoniasis in this country.
\end{abstract}

Keywords: Feline Tritrichomonosis, Large bowel diarrhea, Enteric pathogen

\section{Background}

Tritrichomonas foetus is a protozoal parasite in the order Trichomonadida, and family Trichomonadidae (Phylum Parabasalia) which also includes the genera Trichomonas, Ditrichomonas and Pentatrichomonas [1]. Originally described as a parasite restricted to the urogenital tract of cattle, $T$. foetus has more recently been shown to infect the gastrointestinal tract of domestic cats [2]. $T$. foetus has been reported to be a naturally occurring pathogen of the large intestine of domestic cats that colonizes the ileum, cecum, and colon, and resides in close contact with the epithelium, causing chronic large bowel diarrhoea [3, 4].

\footnotetext{
* Correspondence: alineshora@gmail.com

${ }^{1}$ Department of Preventive Veterinary Medicine and Animal Health, College of Veterinary Medicine, University of São Paulo, São Paulo, SP, Brazil Full list of author information is available at the end of the article

T. foetus has been diagnosed in the domestic cat in many geographic regions including Europe (Austria, Finland, France, Germany, Greece, Italy, the Netherlands, Norway, Poland, Spain, Sweden, Switzerland, and the UK), North America (Canada and the USA), Australia/Oceania (Australia and New Zealand), and Asia (Japan and South Korea) [5]. In Brazil, to date, infection with $T$. foetus has been reported only in asymptomatic cats [6]. This case report describes a case of naturally occurring $T$. foetus infection in a kitten inhabiting in Brazil, São Paulo state and the molecular analysis of this strain.

\section{Case presentation}

A seven-month-old, entire male domestic shorthair kitten was presented to the Veterinary Hospital of the School of Veterinary Medicine - University of São Paulo, Brazil, in October 2013. This cat had a six-month 
history of persistent large intestinal diarrhoea, faecal incontinence, prostration, apathy and weight loss. Previously to the cat presentation at the Veterinary Hospital of the School of Veterinary Medicine, the cat was presented to veterinary practitioners and several different anthelminthics, metronidazole and sulfadimetoxin (dosage not available) were blindly administrated without success. The cat had been confined indoor, and had contact with three asymptomatic cats and a dog. Unfortunately, it was not possible to evaluate the contacting animals due to low compliance of the owner.

At physical examination, the cat showed sensibility to abdominal palpation in the mesogastric region, thickened bowel loops with faecal content, inflammation at the anal region and a body temperature of $39.2{ }^{\circ} \mathrm{C}$. Screening tests for feline leukaemia virus - FeLV and feline immunodeficiency virus - FIV (SNAP FIV/FeLV Combo Test, Idexx Laboratories) were performed and the results were negative.

Faecal flotation was negative for the presence of nematode eggs, Giardia species cysts and coccidian oocysts using sugar centrifugation flotation as previously described [7].

The fresh faecal sample obtained via colon flush was suspended in an equal volume of normal saline and microscopically examined under a cover slip using 200X and 400X magnification. Tritrichomonas sp. was identified by direct examination, which revealed very large numbers of motile trophozoites featuring a pyriform body, which measured approximately 10 to $20 \mu \mathrm{m}$ in length, with three free anterior flagella, an undulating membrane running the length of the body and one posterior flagellum (Fig. $1 \mathrm{a}$ and $\mathrm{b}$ ). The trophozoites exhibited jerky, progressive forward motion (Additional file 1: Movie S1). The motile characteristics of T. foetus differ from Giardia sp. in that a falling leaf motility has been observed [5].
Both T. foetus and Pentatrichomonas hominis can occur in the intestinal tract of cats [6]. P. hominis lives as a mere commensal in the colon of cats [8] and a number of other mammalian hosts including humans, pigs, dogs, water buffalos, cows, and goats [9]. Tritrichomonas sp. and Pentatrichomonas sp. are not easily differentiated from one another by examining living material or organisms stained with routinely used histological stains [10]. Thus, molecular methods to detect $T$. foetus and Pentatrichomonas sp. were performed.

DNA was extracted directly from the fresh faecal sample using a commercial DNA extraction kit (DNeasy Blood \& Tissue, Qiagen), according to the manufacturer's protocol. $T$. foetus and $P$. hominis were tested using the primers and conditions previously described by Felleisen et al. [11] and Crucitti et al. [12], respectively.

Coinfection with $T$. foetus and $P$. hominis was not observed herein, unlike the prior study conducted in Brazil, in which three of the four T. foetus-positive cats were infected with $P$. hominis, although both studies using the same set of primers for the molecular diagnosis of both infections [6]. The amplicon corresponding to $T$. foetus (347 bp) was purified using ExoSAP-IT PCR Product Cleanup (USB Products Affymetrix, Cleveland, $\mathrm{OH})$ and submitted to bidirectional DNA sequencing with BigDye 3.1 (Applied Biosystems, Carlsbad, CA), according to the manufacturer's protocols. The products were resolved using a 3500 Genetic Analyser (Applied Biosystems, Foster, CA), and the electropherograms were analysed with Phred at http://asparagin.cenargen.embrapa.br/phph/. Positions with a quality score of $>20$ were used to generate contiguous sequences with Cap-Contig implemented in the software Bioedit 7.0.9.0 [13]. The sequence was then submitted to BLAST/n at http:// www.ncbi.nlm.nih.gov/BLAST to confirm the amplicon identities. Each sequence was aligned with homologous sequences from $T$. foetus retrieved from GenBank with CLUSTAL/W in Bioedit 7.0.9.0, and a phylogenetic tree

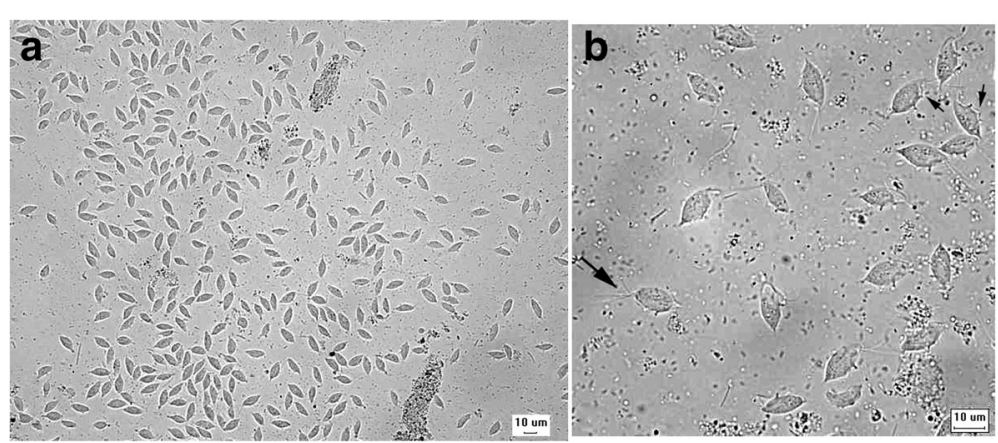

Fig. 1 Tritrichomonas foetus in cat faeces. a Numerous pyriform trophozoites. $\mathbf{b}$ The three free anterior flagella (large arrow) and the undulating membrane (small arrows) can be visualised in some trophozoites. Fresh preparation in saline $0.85 \%$ 


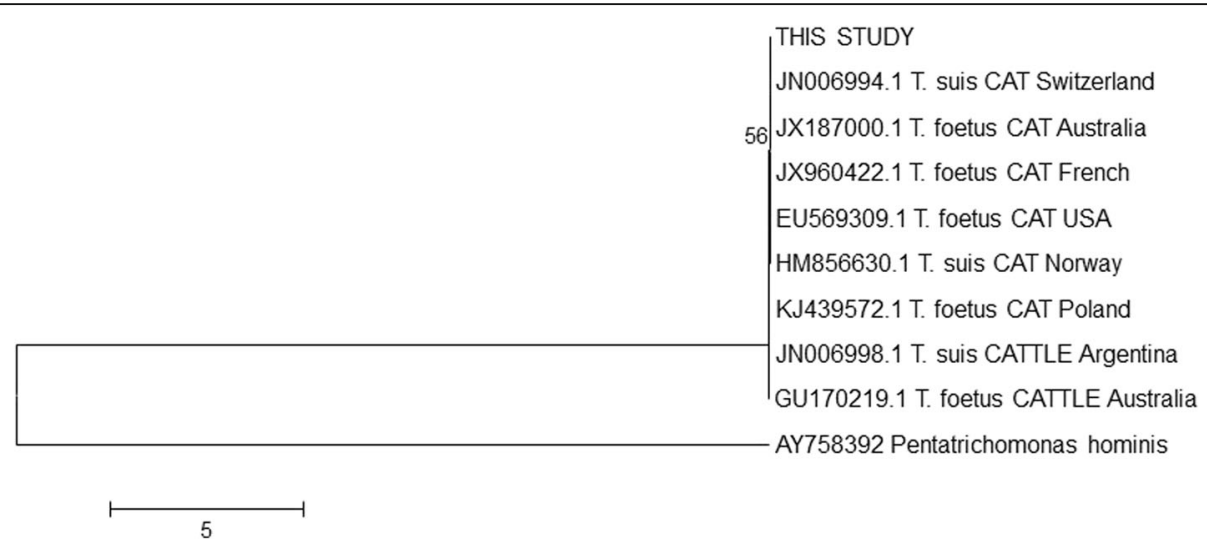

Fig. 2 Neighbor-joining maximum composite likelihood phylogenetic tree of partial sequences of Tritrichomonas foetus and T. suis internal transcribed spacer 1 (partial), 5.85 ribosomal RNA gene (complete), and internal transcribed spacer 2 (partial). Pentatrichomonas hominis was used as an outgroup. The numbers on the nodes indicate the bootstrap support from 1000 replications. Only bootstrap values of $>50$ are shown. The scale bar represents the number of substitutions per nucleotide

for the nucleotide sequences was generated using the neighbor-joining distance algorithm and the maximum composite likelihood model with 1000 bootstrap replicates using MEGA 5.0 [14]. A sequence identity matrix was performed with Bioedit 7.0.9.0. The nucleotide sequence determined in this work was submitted to GenBank under accession number KU680816.

Feline isolates and bovine isolates are morphologically indistinguishable [15]. Current evidence suggests that $T$. foetus and T. suis appear to correspond to the same species [15-18], as observed herein (Fig. 2). This finding is also sustained by a minor difference $(0.04 \%)$ in identity in the sequences from T. foetus (KJ439572, GU170219) and T. suis (JN006998) retrieved from GenBank compared to the sequence from this study.

The kitten was treated with $30 \mathrm{mg} / \mathrm{kg}$ of ronidazole, administered orally once a day for 14 days, which resulted in improvement in faecal consistency and frequency without adverse effects. However, adverse effects, such as reversible neurological signs, including lethargy, trembling of extremities, ataxia, agitation, facial tremors and hyperesthesia, have already been observed in cats treated with this drug [19].

\section{Discussion and Conclusions}

In recent years, $T$. foetus has become increasingly recognized as an important enteric pathogen of cats. A wide geographical distribution of this pathogen has been observed [5], in South America, T. foetus has previously been detected in asymptomatic cats in Brazil [6]. This is the first clinical case of intestinal trichomoniasis caused by $T$. foetus in Brazil and South America, confirming the presence of this pathogen in this part of the world and highlighting the importance of this protozoa being considered in the differential diagnosis of cats presenting diarrhoea of the large intestine. Our case report enriches our knowledge on the geographical distribution of T. foetus in cats in Brazil and provides further understanding of the clinical significance of feline intestinal trichomoniasis in this country.

\section{Additional file}

Additional file 1: Tritrichomonas foetus in cat faeces. Fresh preparation in saline $0.85 \%$. The trophozoites exhibited jerky, progressive forward motion. (MOV 39828 kb)

\section{Abbreviations}

FeLV: Feline leukaemia virus; FIV: Feline immunodeficiency virus; T. foetus: Tritrichomonas foetus; T. suis: Tritrichomonas suis

\section{Funding}

We are very grateful to the Fundação de Amparo à Pesquisa do Estado de São Paulo, Brazil (Grants no. FAPESP 2014/01919-0) and the Coordenação de Aperfeiçoamento de Pessoal de Nível Superior (Grant no. CAPES/PROEX 1841/2016) for funding this research.

Availability of data and materials

The nucleotide sequencing data supporting the results of this article are available in the GenBank ${ }^{\circledast}$ repository, http://www.ncbi.n/m.nih.gov/nuccore/KU680816.

\section{Authors' contributions}

ASH performed biomolecular tests and sequencing analysis. SIM performed clinical pathology tests. FCC handled the case when first presented to the Veterinary Hospital of the School of Veterinary Medicine - University of São Paulo, Brazil. PEB supervised the activities and contributed to the draft. ARJ supervised the clinical activities. HFJP performed parasitological testes, DNA extraction and contributed to the draft. All authors read and approved the final manuscript.

\section{Competing interests}

The authors declare that they have no competing interests.

\section{Consent for publication}

Consent was obtained from the owner of the cat for publication of this case report and any accompanying images and video.

\section{Ethics approval and consent to participate}

The patient's owner provided written, informed consent for the clinical assessment, diagnostic work-up, treatment and follow-up of their pet. This study has been approved by Commission on Ethics on Animal Use from School of Veterinary Medicine, University of São Paulo (under the protocol \# 3577280814). 


\section{Publisher's Note}

Springer Nature remains neutral with regard to jurisdictional claims in published maps and institutional affiliations.

\section{Author details}

${ }^{1}$ Department of Preventive Veterinary Medicine and Animal Health, College of Veterinary Medicine, University of São Paulo, São Paulo, SP, Brazil. ${ }^{2}$ Department of Veterinary Medicine, College of Veterinary Medicine, University of São Paulo, São Paulo, SP, Brazil. ${ }^{3}$ Veterinary Hospital, College of Veterinary Medicine, University of São Paulo, São Paulo, SP, Brazil.

Received: 31 March 2016 Accepted: 3 April 2017

Published online: 17 April 2017

\section{References}

1. Frey CF, Müller N. Tritrichomonas-systematics of an enigmatic genus. Mol Cell Probes. 2012;26:132-6.

2. Slapeta J, Müller N, Stack CM, Walker G, Lew-Tabor A, Tachezy J, et al. Comparative analysis of Tritrichomonas foetus (Riedmüller, 1928) cat genotype, T. foetus (Riedmüller, 1928) cattle genotype and Tritrichomonas suis (Davaine, 1875) at 10 DNA loci. Int J Parasitol. 2012;42:1143-9.

3. Gookin JL, Levy MG, Law JM, Papich MG, Poore MF, Breitschwerdt EB. Experimental infection of cats with Tritrichomonas foetus. Am J Vet Res. 2001;62:1690-7.

4. Xenoulis PG, Lopinski DJ, Read SA, Suchodolski JS, Steiner JM. Intestinal Tritrichomonas foetus infection in cats: a retrospective study of 104 cases. J Feline Med Surg. 2013;15:1098-103.

5. Yao C, Köster LS. Tritrichomonas foetus infection, a cause of chronic diarrhea in the domestic cat. Vet Res BioMed Central Ltd. 2015;46:35.

6. Santos CS, Jesus VLT, McIntosh D, Berto BP, Lopes CWG. Co-infection by Tritrichomonas foetus and Pentatrichomonas hominis in asymptomatic cats. Pesq Vet Bras. 2015;35:980-8.

7. Ogassawara S, Benassi S. Infecção experimental de gatos com coração de bovino parasitado por Sarcocystis sp. Arq Inst Biol (São Paulo). 1980;47:27-32.

8. Gookin JL, Stauffer SH, Levy MG. Identification of Pentatrichomonas hominis in feline fecal samples by polymerase chain reaction assay. Vet Parasitol. 2007:145:11-5.

9. Kamaruddin M, Tokoro M, Rahman M, Moshiur A, APNH S, Syafruddin D, PBS A, et al. Molecular Characterization of Various Trichomonad Species Isolated from Humans and Related Mammals in Indonesia. Korean J Parasitol. 2014;52:471-8.

10. Levy MG, Gookin JL, Poore M, Birkenheuer AJ, Dykstra MJ, Litaker RW. Tritrichomonas foetus and not Pentatrichomonas hominis is the etiologic agent of feline trichomonal diarrhea. J Parasitol. 2003;89:99-104.

11. Felleisen RSJ, Lambelet N, Bachmann P, Nicolet J, Muller N, Gottstein B. Detection of Tritrichomonas foetus by PCR and DNA Enzyme Immunoassay Based on rRNA Gene Unit Sequences. J Clin Microbiol. 1998;36:513-9.

12. Crucitti T, Abdellati S, Ross DA, Changalucha J, Dyck E, Buve A. Detection of Pentatrichomonas hominis DNA in biological specimens by PCR. Lett Appl Microbiol. 2004;38:510-6.

13. Hall TA. Bioedit: a user-friendly biological sequence alignment editor and analysis program for Windows 95/98/NT. Nucleic Acids Symp Ser. 1999;41:95-8.

14. Tamura K, Peterson D, Peterson N, Stecher G, Nei M, Kumar S. MEGA5: molecular evolutionary genetics analysis using maximum likelihood, evolutionary distance, and maximum parsimony methods. Mol Biol Evol. 2011;28:2731-9.

15. Reinmann K, Müller N, Kuhnert $P$, Campero CM, Leitsch D, Hess M, et al. Tritrichomonas foetus isolates from cats and cattle show minor genetic differences in unrelated loci ITS-2 and EF-1a. Vet Parasitol. 2012;185:138-44.

16. Slapeta J, Craig S, McDonell D, Emery D. Tritrichomonas foetus from domestic cats and cattle are genetically distinct. Exp Parasitol. 2010; 126:209-13

17. Sun Z, Stack C, Šlapeta J. Sequence differences in the diagnostic region of the cysteine protease 8 gene of Tritrichomonas foetus parasites of cats and cattle. Vet Parasitol. 2012;186:445-9.

18. Kleina P, Bettim-Bandinelli J, Bonatto SL, Benchimol M, Bogo MR. Molecular phylogeny of Trichomonadidae family inferred from ITS-1, 5.8S rRNA and ITS-2 sequences. Int J Parasitol. 2004;34:963-70.

19. LeVine DN, Papich MG, Gookin JL, Davidson GS, Davis JL, Hayes RB. Ronidazole pharmacokinetics after intravenous and oral immediate-release capsule administration in healthy cats. J Feline Med Surg. 2011;13:244-50.

\section{Submit your next manuscript to BioMed Central and we will help you at every step:}

- We accept pre-submission inquiries

- Our selector tool helps you to find the most relevant journal

- We provide round the clock customer support

- Convenient online submission

- Thorough peer review

- Inclusion in PubMed and all major indexing services

- Maximum visibility for your research

Submit your manuscript at www.biomedcentral.com/submit 